\title{
The Role of Supervisor in DevelopingSubordinates in the Sudanese Electricity Distribution Company.
}

\author{
Saad Mohamed Ahmed Ali \\ Department of Administrative Sciences, College of Community, University of Najran, Saudi Arabia
}

\begin{abstract}
Abstract: This study was carried out to identify the role of supervisor in developing subordinates in the Sudanese Electricity Distribution Company (SEDC) as a model for the rest of public companies in Sudan. The study draws the attention of specialists in the field of supervision to the importance of their roles in developing subordinates. In this study deductive approach, analytical and descriptive methods were used (questionnaire, observation). A simple closed endedquestionnaire divided into two sections, section (1) to collect demographic data about the sample population (gender,age, ..ect) and section (2) consist of 12 questions to help the respondentanswering how strongly he agrees or disagree to each statement. This questionnairewas distributed to 77 individuals. Seventy six completed questionnaire were recovered which represent a recovery rate of $98.7 \%$. The data were uploaded into tables especially prepared for this purpose, where the nominal variables (strongly agree, agree, agree to a certain extent, disagree, strongly disagree) were converted into numerical variable $(1,2,3,4,5)$, respectively. The opinion of respondents vary significantly $(\mathrm{p}<0.001)$ withtheir high school qualification, the number of high degrees holders who agree to this $(30.3 \%)$ hold master $(36.9 \%)$ hold B.sc $(10.5 \%)$ hold Pgd $(5.2 \%)$ hold PhD.

It is concluded from this study that the styles of supervision, satisfaction of subordinate needs, subordinate's on the job training are very essential for developing and promoting the subordinates.
\end{abstract}

\section{INTRODUCTION:}

The motivation of subordinates to unify, cooperate and strive to carry out tasks is an elusive issue that only a resourceful, skilled and experienced supervisor who can understand the different behaviors and attitudes of subordinates, and recognize their personalities,can achieve this. The mere existence of that successful supervisor only is not enough; however it's also necessary for subordinates to be of high level of knowledge, skill and ability to accomplish their jobs. It is natural that the degrees of knowledge and skills of subordinates vary even in one administrative unit due to disparity in qualification and experience of each subordinate based on previous experiences. In any enterprise serious, medium newly employed subordinates without experience can be found. These disparities lead to unequal abilities, performance and productivity.

As part of the supervisor effort to achieve the performance level required in any administrative unit, the supervisor should strive to promote subordinates especially the new ones who are in need of more knowledge, skill and abilities to execute their tasks, therefore the supervisor has to pave the way for subordinates and encourage them to identify the drives they need, in a clear and continuous path, the supervisor must guide his subordinates towards a comprehensives development up to the best of their level of development and performance.Eventually he enables them achieving their desires, actualize themselves and prepare them to become heads and team leaders in the future.

It is certain that supervisors will reap the fruits of developing their subordinates in further commitment and loyalty to the organization, cooperation, more improvement in performance and an increase in their productivity, which in turn will help in achieving the overall goal of organization and ultimately lead to the work stability and continuity of work survival.

Supervisors generally have several methods and means to develop the knowledge, skills and behaviors of the subordinates; they can lead by example, coaching and mentoring them on-the-job and advise them by counseling, evaluating and correcting errors in a role model example not as a chief only.No doubt the success of subordinate is the success of the supervisor and any improvement in subordinate performance accompanied with an increase in productivity of the unit, ultimate to superiors. Therefore the required effort from supervisor is not optional or voluntarily task, but it is the core of his job, so the supervisor must not waste an effort and time to promote and train his subordinates, especially the newly employed ones in order to avoid any losses that may arise from inexperience and lack of skills.Finally the supervisor must protect his administrative unit from all kinds of devastating work sicknesses, such as anxiety, dissatisfaction, hatred of work, poor performance, poor productivity and loss of working staff quitting. 


\section{LITERATURE REVIEW:}

Several studies have been carried out to identify and analyze the numerous factors related to supervisor's roles that affect subordinates career and performance development. Jie-Tsuen\&Hui-Hsien(2015) conducted study to investigate the effects of coaching on employees' in-role behaviors (IRBs) and proactive career behaviors, and explored the mediating role of psychological empowerment. Jennifer \&Chris (2001)studiedthe role of the supervisor in career and organizational commitment. This study investigated relationships between supervisor support activities and their subordinates' career and organizational commitment. Isa \&Jailani(2014) studied the supervisor's role for improving the quality of teaching. The aim of this study was to assess the general roles of school supervisors in improving teaching quality and effectiveness of schools supervision. Ding-Yu\&Bor-Shiuan(2008) studied the affectand role-based loyalty to supervisors as two distinct types of loyalty to supervisors as an important factor in Chinese organizations.Kehinde\& Somoye(2011) conducted study on the effect of roles and duties of managers on organization performance. Dorothea(2015) conducted study to identify the relationship between supervisor and co-workers, psychological condition and employee engagement in the workplace; in particular this study aims to test models of influence psychological conditions on employee engagement in the workplace. Brad \&Leila (2012) studied the relationship between supervisor behavior and employee presenteeism. This study aimed to closely aligned with a question such as, "does whether someone is perceived by employees to be a good or bad boss affect employees' presenteeism?" than it is with a question such as, "does transactional or transformational leadership show stronger associations with presenteeism?.Wael(2015) conducted study on the optimum relationship between managers and employees. The objective of this research was to show how to enhance the relationship between manager and employee. Wińska(2010) conducted study on influence of superiorsubordinate communication on employee satisfaction. Paul etal(2014) examined the extent to which the performance of challenging tasks is related to employees' and supervisors' goal orientations. Izahetal (2012) investigated the effective supervision as one of the factors that determine the success of research students in doing their postgraduate programs. The aim of the study was to identify the attributes of supervisors and examine elements of effective supervision from the graduate research students" perspective.Abdul Hameed (2011) studied and analyzed the theoretical framework \& models related to employee development and its effect on employee performance. Alex etal(2015) investigated the effect of employee development on organizational performance in Ghana's public sector, using the experience of Controller and Accountants General's Department. Mine etal (2015) conducted study on subordinate trust in supervisor and organization: effects onsubordinate perceptions of psychological empowerment. Paul \&Carrie (2010) studied the effects of supervisors' verbal aggressiveness and mentoring on their subordinatesperceived communication satisfaction, job satisfaction, and organizational commitment.The current study investigates the role of supervisor in developing subordinates, regarding behavior, attitude, traits, skills and practices of the supervisor, which was not completely covered by the above mentioned previous studies.

\section{HYPOTHESIS:}

1) There is a positive relationship between the style of supervision and improvement of subordinate behavior.

2) There is a positive relationship between satisfaction of subordinate needs and his excellence \& evolution.

3 ) There is a positive relationship between subordinate's on the job trainingand development of his skills.

\section{PROBLEM STATEMENT:}

The following statements sum up the problem of the study:

1) Qualities, traits and behavior of a model supervisor affect the subordinates' work and behavior.

2) Subordinate emulate supervisor when he applies practical skills with high accuracy in the workplace

3) No interference in subordinates' small or big tasks, enhance their evolution and self-confidence.

4) Allowing subordinate to rely on himself will encourage him to innovate and create.

5) Promoting outstanding subordinate will encourage him for more excellence.

6) Satisfying subordinate needs will eliminate frustration, anxiety, dissatisfaction and hatred of work.

7) Directing erring subordinate with appreciation and respection inspires him to correct his error.

8) Helping subordinate to solve his problems increase his loyalty and love of work.

9) Involving subordinates in decision-making increases their respect and willingness to execute decisions.

10) Delegating authority to subordinate trains and prepare him for future promotion.

11) Enriching subordinate's work improves their skills and experience.

12) Training subordinate on the job and providing him with sufficient information increases his skills and reduces his errors. 


\section{METHODOLOGY \& METHODS:}

Population and sample:

The population of the study was the workers of the SEDC Company as a model for the rest of the Sudanese Electricity Companies. Three levels of employees (department managers, sections managers, operational supervisors) were surveyed with a survey instrument.

Context of the study:

The study is primarily based on the descriptive approach. It also depends on a review of literature regarding supervisor's roles in the development of subordinates used as secondary sources such as books, references, and records to collect the necessary data for the theoretical part of the study. As for the analytical part of the study, the primary sources such as questionnaires and observations were used.

Data collection and analysis:

The survey instrument consisted of two parts: Section I: focused on personal data of the study sample (gender, age, educational qualification, years of experience, specialty, \& career level).Section II: consisted of 12 questions based on supervisor roles that influence subordinates development to be answered according to the Likert 5 scale, which includes five levels (strongly agree, agree, agree to some extent, disagree, strongly disagree). The questionnaire's paragraphs stability was tested according to the methods of Cranach's Alpha. And the consistency was found 0.83 . The survey instrument was handed out to the 77 randomly selected supervisors, managers and deputy managers of the study sample and 76 questionnaires were recovered (recovery rate of $98.7 \%)$.

The data were evacuated into tables especially prepared for the purpose of data ananlysis,and probabilities of 0.05 were considered significant, analysis, demographics data (gender, age, educational qualification, years of experience, specialty, and career level) were designated as independent variables. The dependent variables werestatements of supervisor roles. Data were analyzed using Pearson's chi-square testof (SPSS) Statistical Package for Social Sciences. To show the Nominal relationships/associations between gender, age, educational qualification, years of experience, specialty \& career level) and roles of the supervisor.

\section{Sample profile}

\section{RESULTS AND DISCUSSION:}

Of the 77 questionnaires distributed, 76 were completed and returned, a response rate of $98.7 \%$. The sample of 76 respondents consisted of $23.7 \%$ female and $76.3 \%$ male employees. All of them were full-time employee. When grouped by age $2.6 \%$ were $<30$ years old, $21.1 \%$ were from 30 to less than 35 years, $21.1 \%$ were from 35 to less than 40 years, $55.3 \%$ were from 40 years and above. The subjects of the study sample holds a bachelor (42.1\%),30.3\% hold master degree, 13.2\% hold postgraduate diploma, 6.6\% hold PhD degree, $5.3 \%$ hold intermediate diploma, $2.6 \%$ holds a secondary certificate. The specialties of respondents surveyed are $53.9 \%$ administrative, $38.2 \%$ technical, $7.9 \%$ are from various disciplines. The experience of most of the respondents $(72.4 \%)$ is more than 10 years; from 5 to less than 10 years $(22.4 \%)$ and those with the least experience $\geq 5$ years are $5.3 \%$. The supervisors represent the major career $(34.2 \%)$, followed by directorate managers $(25 \%)$ department managers $(22.4 \%)$, unit managers $(14.5 \%)$ others $(3.9 \%)$, as detailed in table (1). According to the administrative structure of the company the ratio between supervisors and directorate managers is normal.

Table (1). Characteristics of the surveyed sample (frequencies)

\begin{tabular}{llll}
\hline Category & & Frequency & Percent \\
\hline Gender & male & 58 & 76.3 \\
& female & 18 & 23.7 \\
Age & Total & 76 & 100.0 \\
& f 30 years old & 2 & 2.6 \\
& from 30 to less than 35 years & 16 & 21.1 \\
& from 35 to less than 40 years & 16 & 21.1 \\
from 40 years and above & 42 & 55.3 \\
High school attended & Total & 76 & 100.0 \\
& secondary certificate & 2 & 2.6 \\
& intermediate diploma & 4 & 5.3 \\
& bachelor degree & 32 & 42.1 \\
& postgraduate diploma & 10 & 13.2 \\
Specialty & master degree & 23 & 30.3 \\
& PhD degree & 5 & 6.6 \\
& Total & 76 & 100.0 \\
Years of experience & Administrative & 41 & 53.9 \\
& Technical & 29 & 38.2 \\
& others & 6 & 7.9 \\
& Total & 76 & 100.0 \\
& Equal or less than 5 years & 4 & 5.3 \\
& from 5 to less than 10 years & 17 & 22.4
\end{tabular}




\begin{tabular}{|c|c|c|c|}
\hline \multirow{8}{*}{ Position } & 10 years and above & 55 & 72.4 \\
\hline & Total & 76 & 100.0 \\
\hline & directorate managers & 19 & 25.0 \\
\hline & department managers & 17 & 22.4 \\
\hline & unit managers & 11 & 14.5 \\
\hline & supervisor & 26 & 34.2 \\
\hline & others & 3 & 3.9 \\
\hline & Total & 76 & 100.0 \\
\hline
\end{tabular}

\section{Results:}

This part discusses the results of this study and its findings in light of previous relevant research and provides its recommendations for supervisors and managers work in SEDC Company and similar organizations.

Graph (1) Assumption of responses on statements (\%)

\section{Percentages of Responses}

- Strongly agree $\quad$ Agree $\quad$ Agree to some extent $\quad$ Disagree $\quad$ Strongly disagree

(1)qualities, traits and behavior of a model supervisor affects the subordinates' work and behavior

(2)subordinate emulate supervisor when he applies practical skills with high accuracy in the workplace

(3)no interference in subordinates' small or big tasks, enhance their evolution and self-confidence

(4)allowing subordinate to rely on himself will encourage him to innovate and create

(5)promoting outstanding subordinate will encourage him for more excellence

(6)satisfying subordinate needs will eliminate frustration, anxiety, dissatisfaction and hatred of work

(7) directing erring subordinate with appreciation and respection inspires him to correct his error

(8)helping subordinate to solve his problems increase his loyalty and love of work

(9)involving subordinates in decision-making increases their respect and willingness to execute decision

(10)delegating authority to subordinate trains and prepare him for future promotion

(11)enriching subordinate's work improve their skills and experience

(12)training subordinate on the job and providing him with sufficient information increases his skills and reduces his errors

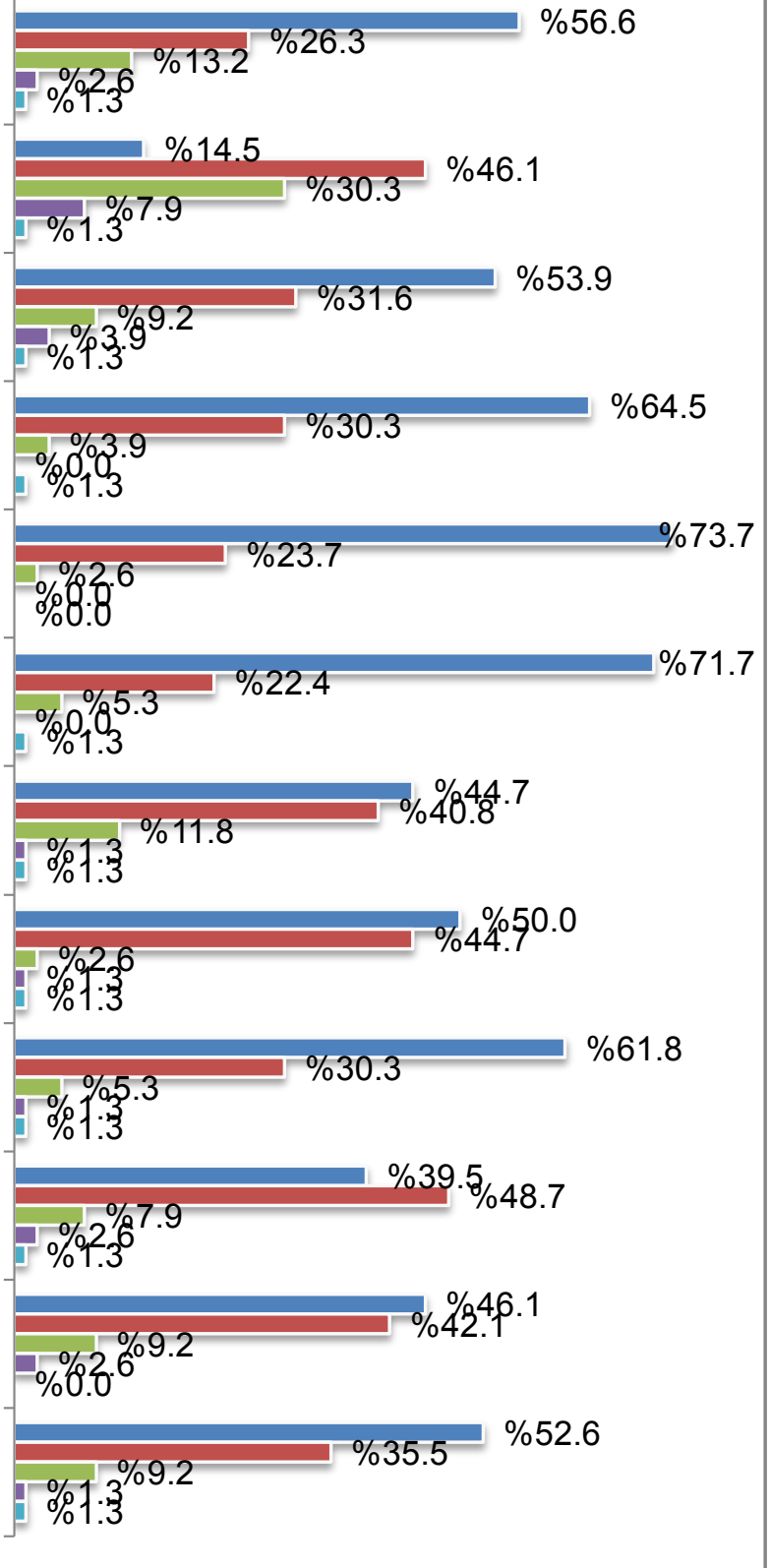

Table (2) Items Statistics: 


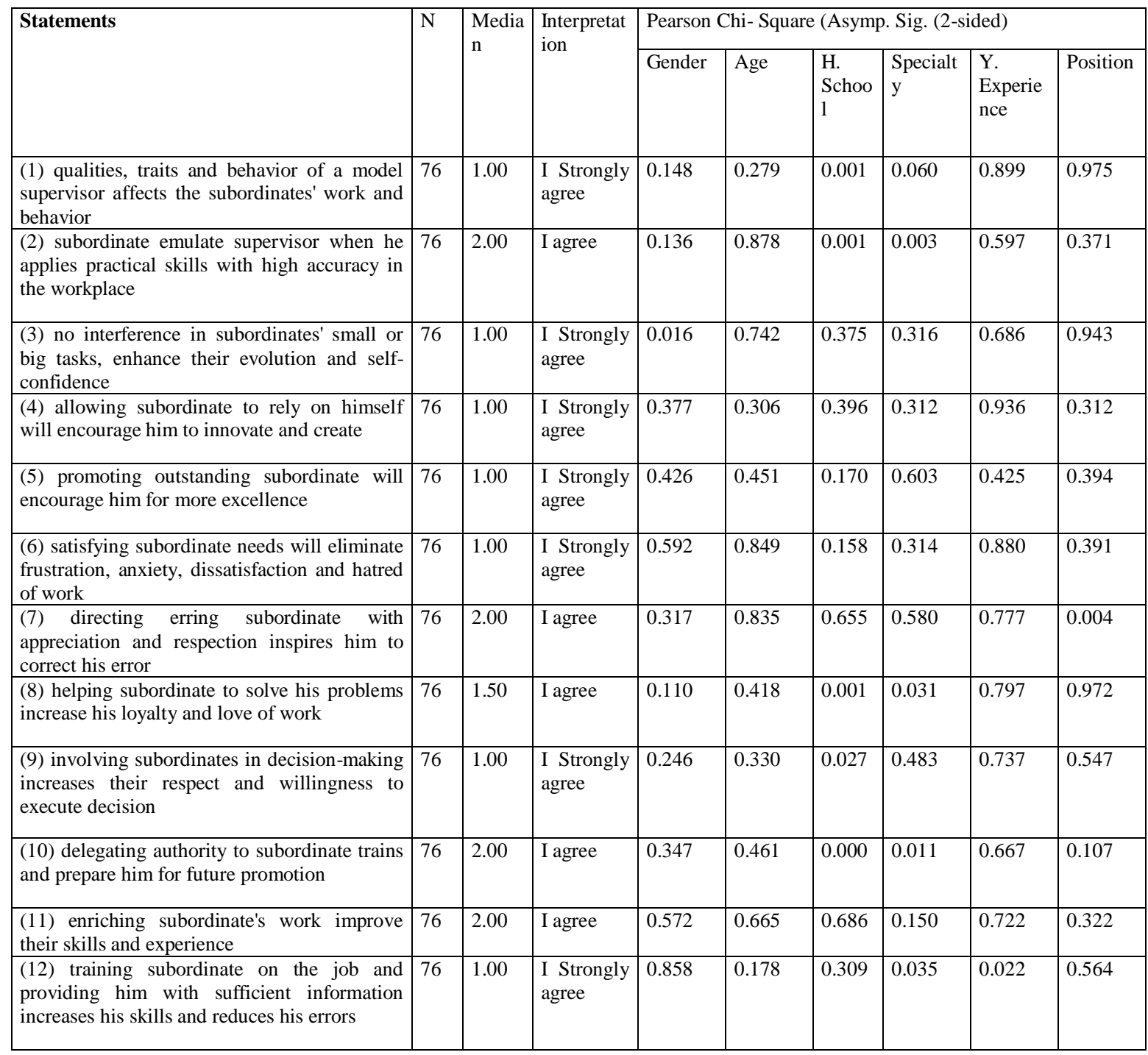

When reading table (2) we are interested in the results of the "Pearson Chi-Square" columns. We can see in respondent Gender column that P:value for most statements $>0.05$ This tells us that there is no statistically significant association betweenrespondents Gender and their answers, except statement no (3) for which p: value $=(0.016)$ which shows statistically significant association between respondents Gender and their answers. This statement realized in favor of those who strongly agree, but the significance can be attributed to opinions of both males and females who disagree with the statement and see that is it sometimes necessary for supervisorsto interfere in subordinates tasks. In respondent age column p: value for all statements $>0.05$, this tells us that there is no statistically significant association betweenrespondents age and their answers to statements and this should not be a cause for concern. While in respondent high school qualifications column p:value for most statements $>0.05$ this tells us that there is no statistically significant association betweenrespondents high school qualifications and their answers, except statement $(1,2,8,9 \& 10)$ for which p:value $<0.05$ whichtells us that there is statistically significant association between respondents high school qualification and their answers.Statements $(1,8,9)$ were realized in favor of those who strongly agree, and statements $(2,10)$ were realized in favor of those who agree, but the significance can be attributed to opinions of holders of higher degrees who disagree with these statements and see the contrary.

In respondent specialty column p:value for most statements $>0.05$, this tells us that there is no statistically significant association betweenrespondents specialty and their answers, except statement $(2,8,10, \& 12)$ for which p:value $<0.05$ whichtells us that there is statistically significant association between respondents specialty and their answers. Statements $(2,10)$ were realized in favor of those who agree, while statements $(8,12)$ were realized in favor of those who strongly agree.But thissignificance can be attributed to opinions of some nonadministrative supervisorswho disagree with these statements and see the contrary.In respondent experience column p:value for most statements $>0.05$, this tells us that there is no statistically significant association between respondents experience and their answers except statement (12) for which p:value (0.022) which tells us that 
there is statistically significant association between respondents experience and their answers. This statement was realized in favor of those who strongly agree, but the significance can be attributed to opinions of some experienced supervisors who disagree with the statement that on the job training only is not enough to increase skill and reduce errors, therefore other ways should be followed to develop subordinates.In respondent career level column p:value for most statements $>0.05$, this tells us that there is no statistically significant association between respondents experience and their answers, except statement (7) for which p:value (0.004) which tells us that there is statistically significant association between respondents career level and their answers. This statement was realized in favor of those who strongly agree.But this significance can be attributed to opinions of some directorate managerswho disagree with the statement that directing erring subordinate with respectionand appreciation only is not enough to correct his errors and see that other methods of direction must be followed for correcting erring subordinates.

\section{DISCUSSION}

The findings of this study emphasized the unlimited role of a qualified,skillful,and expertise supervisor in developing subordinates. Furthermore the findings revealed a consensus amongthe surveyed staff's sample that a skillful supervisor who choose best styles of supervision, satisfy needs of subordinates, and train his subordinateshas a positive effect on subordinates behavior, skills, attitudes and performance in the workplace.

There is also an agreement, among the field writers, and as seen from the literature review on the effect of supervisor role on subordinates behavior, skills, attitudes and performance in the workplace.According to this study the supervisor's roles and practices are related to subordinates promotion. This is due to the fact that good practices of supervision lead to good performance of employees. This study empirically established evidence for the existence of positive relationship between the styles of supervision; including the traits of supervisor, interference in subordinate work when necessary, encouraging subordinate to rely on himself, practicing good methods of directions, delegating authority to subordinates, helping subordinate to solve problems, and the development of subordinates. This means that supervisors are well aware of their roles which is expected to lead to more improvement in performance and productivity in the future and must be considered when preparing training plans for supervisors, this result agree with the results of a study conducted byJennifer \& Chris (2001) on the role of the supervisor in career and organizational commitment where their study has revealed thatemployees who see their supervisors as giving them trust and the authority to do the job were more committed to their organization, as were those who perceived their supervisors to engage in feedback and goalsetting. This result also agrees with the results of another study conducted byBrad \& Leila (2012) on the link between supervisor behavior and employee presenteeism, where their study has revealed thatthe Internalconsistency reliability and discriminant validity for the measures of job-stress-related presenteeism and the two dimensions of supervisor behavior were acceptable. This result also agrees with the results of another study conducted byMine Afacan et al (2015) on subordinate trust in supervisor and organization: effects onsubordinate perceptions of psychological empowerment, where theirstudy revealed a strong and positive relationship between trust in supervisor and the subordinate perceptions of psychological empowerment in terms of meaning and competence factors. This result also agrees with the results of Paul \&Carrie (2010) who studiedthe effects of supervisors' verbal aggressiveness and mentoring on their subordinatesperceived communication satisfaction, job satisfaction, and organizational commitment, where their study indicated positive relationships between mentoring behaviors by supervisors and their subordinates' communication satisfaction, organizational commitment, and job satisfaction, and negative relationships between supervisors' verbal aggression and their subordinates' communication satisfaction, organizational commitment, and job satisfaction.

The study also shows that satisfaction of subordinate tangible and intangible needs, encouraging them, and enriching their jobs positively affect the development of subordinates. This means that motivations system must be active andmust continuously be improved to keep employees loyal to their organization because of economic changes that affects the labor market.This result agrees with the results of Dorothea (2015) inhis study on the relationship between supervisor and co-workers, psychological condition and employee engagement in the workplace where his study has revealed that there is mediating model of psychological conditions on the relationship between supervisor relations, co-worker relations and employee engagement. This result also agrees with the results of Joanna (2010)in her study on the internal communication between the supervisor and subordinate and its impact on job satisfaction, where herstudy concluded that supervisors who are communicatively competent are likely to be perceived as leaders by their subordinates, which in turn may result in positive employee and organizational outcomes.

This study also revealed thatsubordinate's on the job training, and providing him with all needed information, develop his skills and reduces his errors. This means that supervisors are playing important role as coaches, and this must motivate organizations to continuously train supervisors who are in turn train subordinates, this result is in agreement with the results of the study conducted byJie-Tsuen\&Hui-Hsien, (2015)in their study on the 
effects of coaching on employees' in-role behaviors (IRBs) and proactive career behaviors, where their study has revealed that coaching was positively related to both IRBs and PCBs.

\section{CONCLUSIONS AND RECOMMENDATIONS:}

The conclusion to be drawn from this study is that good styles of supervision, satisfaction of subordinate needs, subordinate's on the job training are very essential for developing and promoting the subordinates in public organization.Therefore, the quest of the researcher, as indicated in the title of the research, for a relationship between the role of supervisor and development of subordinate is met.

The following recommendations are the contribution of this study

1) Supervisors should be specialized and holders of high qualifications.

2) Supervisors should delegate some authorities to subordinates to prepare them for future opportunities.

3) The company must train supervisors in good practices and styles of supervision.

4) The company and supervisors must consider satisfying needs of subordinates.

5) The supervisor must be good coaches for subordinates in the workplace.

6) Methods of developing subordinates in the company must be diversified.

7) Supervisors must closely supervise subordinates, and direct them when necessary.

8) Subordinateshave to acquire good behaviors from model supervisors.

\section{ACKNOWLEDGEMENTS:}

Thanks to the top management of Sudanese Electricity Distribution Company and its Staff who agreed to participate in this study. Thanks are also due to Prof. AdilSalimElshiekh for assisting with the advices and analysis.

\section{REFERENCES:}

[1] Jie-TsuenHuanga\&Hui-Hsien Hsieh, (2015) Supervisors as good coaches: influences of coaching on employees' in-role behaviors and proactive career behaviors. The International Journal of Human Resource Management, Vol.26,No.1,42-58

[2] Kehinde James Sunday \&Somoye R. O. C (2011) Organization Performance: The Roles and the Duties of Managers, journal of African Microeconomic review, Vol. 1, No. 1 (2011) ISSN 2220 -945X

[3] Isa YugudaKotirde\&Jailani Bin Md (2014) The supervisor's role for improving the quality of teaching and learning in Nigeria secondary school educational system, International Journal of Education and Research, Vol. 2 No. 8 August 2014

[4] Ding-Yu Jiang \&Bor-Shiuan (2008) Affect-and role-based loyalty to supervisors in Chinese organizations, Asian Journal of Social Psychology , DOI:10.1111/j.1467-839X.2008.00260.x

[5] Dorothea WahyuAriani (2015) relationship between supervisor and co-workers, psychological condition and employee engagement in the workplace, Journal of Business and Management, Volume 4, Issue 3 (2015), 34-47

[6] Brad Gilbreath\& Leila Karimi (2012) supervisor behavior and employee presenteeism, International Journal of Leadership Studies, Vol. 7 Iss. 1, 2012, 114-131.

[7] Joanna Wińska, (2010) influence of superior-subordinate communication on employee satisfaction, Journal of positive management, Vol.1, No. 1, 2010, pp. 110-124

[8] IzahMohdTahir, Norizan Abdul Ghani, EngkuSuhaimiEngkuAtek, Zulkifli A Manaf (2012) Effective Supervision from Research Students' Perspective, International Journal of Education ISSN 1948-5476, 2012, Vol. 4, No. 2

[9] Paul Preenen, Annelies van Vianen\& Irene de Pater (2014) Challenging tasks: The role of employees' and supervisors' goal orientations, European Journal of Work and Organizational Psychology, Vol.23,No.1,-4861

[10] Abdul HameedAamerWaheed (2011) employee development and its affect on employee performance a conceptual framework, International Journal of Business and Social Science Vol. 2 No.13 [Special Issue July 2011]

[11] Alex Anlesinya, ZakariBukari\& Patrick Eshun (2015) The Effect Of Employee Development On Performance Of Public Sector Organisations In Ghana: Evidence from Controller and Accountant General's Department, Accra, International Journal of Management and Commerce Innovations ISSN 2348-7585, Vol. 2, Issue 2, pp: (283-290), Month: October 2014 - March 2015,

[12] Wael M. EL NabawySalehDewydar (2015) the optimum relationship between managers and employees, International Journal of Business and Social Science, Vol. 6, No. 8; August 2015

[13] Jennifer M. Kidd \& Chris Smewing (2001) The role of the supervisor in career and organizational commitment, European Journal of Work and Organizational Psychology, Volume 10, 2001 - Issue 1, pp 
[14] Mine Afacan FINDIKLI, Adem Gulden \& FatihSemercioz, (2015) subordinate trust in supervisor and organization: effects on subordinate perceptions of psychological empowerment, international journal of business and management studies, Vol 2, No 1, 2010 ISSN: 1309-8047

[15] Paul E. Madlock\& Carrie Kennedy-Lightsey (2010) the effects of supervisors' verbal aggressiveness and mentoring on their subordinates, Journal of Business Communication, Volume 47, Number 1, January 2010 42-62 